\title{
The devil in the details: public health and depression
}

\author{
Andreas Vilhelmsson* \\ *Correspondence: andreas.vilhelmsson@med.lu.se \\ Edited by: \\ ClarLynda Williams-DeVane, North Carolina Central University, USA \\ Reviewed by: \\ Catherine M. Crespi, University of California Los Angeles, USA \\ Divy Ravindranath, Palo Alto VA Health Care System, USA
}

Department of Clinical Sciences, Division of Social Medicine and Global Health, Faculty of Medicine, Lund University, Malmö, Sweden

Keywords: depression, medicalization, mental disorders, overdiagnosis, overtreatment, public health

\section{BACKGROUND}

Mental disorders have been increasingly portrayed by the World Health Organization (WHO) and health researchers as a growing burden to global public health (1$5)$. Just the sheer economic impact of mental disorders is significant; it is expected to cost almost a third of the projected US $\$ 47$ trillion incurred by all non-communicable diseases by 2030 (6). American and European research indicated in 2005 that 26$27 \%$ of the adult population suffers from a diagnosable mental disorder, representing over 57 million Americans and almost 83 million Europeans $(7,8)$. The European research was later revised in 2011 to $38 \%$ (approximately 160 million Europeans) by including mental diagnoses usually not analyzed in these kinds of studies, such as insomnia and alcoholism (9). In Sweden as well as other countries, milder mental symptoms are now being frequently reported as common occurrences $(10,11)$, especially among youth and the elderly (12, 13). These milder symptoms are increasingly becoming highlighted as important; research (for example, Swedish and American) have suggested that early mental ill health can predict more severe mental illness and mental disorders (such as major depression) later in life (14-16) and even premature death (17). It is, therefore, often argued that early signs of mental ill health need to be acknowledged and treated to prevent the onset of mental disorders (14-16, 18-21).

Depression is the most common of the affective disorders, which are defined as disorders of mood rather than disturbances of thought or cognition (22). Depression is estimated to have a point prevalence of about $5 \%$ in the general population, and a lifetime risk of about 15\% (23). Globally, more than 350 million people of all ages are believed to suffer from depression (24). Just in the European Union, a yearly prevalence of $6.9 \%$ of depression is estimated to affect 30.3 million inhabitants (9).

Overall, the WHO now ranks depression as one of the most burdensome diseases in the world, and the organization has for some time projected and warned that depression is predicted to be the highestranking disease problem in the developed world by $2020(1,2)$.

This description is, however, not without controversy, and some scholars are skeptical of how, for instance, depression is viewed as an increasing widespread ill health problem (25-29). The aim of this article is to discuss some of these issues.

\section{DISCUSSION}

\section{THE ANATOMY OF PUBLIC HEALTH}

As Dubos argues in his classic book Mirage of Health, the myths of Hygeia and Asclepius symbolize the never-ending oscillation between two different points of view in medicine: health as the natural order of things and health as something to be restored by correcting an imperfection (30). The modern followers of Hygeia can be understood as practitioners of public health and the medical professionals as followers of Asclepius (31). It is sometimes argued that with the exception of the specialties of public health and family medicine, the focus of modern medicine is mainly on the individual patient, rather than relating their situation to their families, communities, or the wider society (32). However, while public health medicine has long engaged in strategies of disease prevention and health promotion, more individualized practices of risk are argued to have become a central dimension of the politics of life in the twenty-first century (33). Increasingly, we have come to regard simply being at risk of future disease as being a disease in its own right (28). Diagnostic labels now go beyond disease itself to include risk factors for disease, sometimes giving rise to a new source of social identity, namely a pre-disease (34). This is what critics argue is underway with the introduction of preconditions for major depression in DSM-5 (35). Focusing on preconditions for disease may further increase what the German sociologist, Ulrich Beck, has called the "risk society" (36) and in a global approach "world risk society" (37); a society structured through individualization where a social crisis appears as an individual crises, no longer perceived in terms of their rootedness in the social realm. Thinking of depression in terms of risk is related to the problematization of depressive illness in the population and as a public health issue (38). But by trying to assess potential risk factors for disease and disorders at earlier stages, the concepts of illness and risk may become increasingly blurred (39).

\section{THE GHOST IN THE MACHINE}

A medical diagnosis is perhaps most readily recognized as the official label that classifies disease as a medically related problem, and is the foundation from which sensemaking and experiences are crafted (34). A diagnosis can validate a patient's perception of her symptoms by giving her experience a name, and equally, it can pathologize routine lived experience, such as fluctuations in one's mood (40). Medical encounters usually take place within a system where diagnostic handbooks and short form tests are used as a fast way of judging a person's health status, a system that allows 
and encourages doctors to swiftly choose a diagnosis without a comprehensive investigation of the whole situation surrounding the patient. As argued, for instance, by psychiatrist David Healy, guidelines and protocols are now part of an "industrialization of health care" as he calls it (41). This is not the purpose for which these handbooks were intended. The DSM was issued as a manual for guiding decisions regarding diagnosis, but has more often been used as a steering document for diagnosis. For instance, it is stated in the DSM-IV that, "It is important that DSM-IV not to be applied mechanically ... and are not to be used in a cookbook fashion" (p. xxxii) (42). By using the DSM as a "fast track" to diagnosis, one may end up with a problem with not just overdiagnosis, but also overtreatment. In the medical encounter, the doctor may judge it to be more dangerous not to treat someone who may prove to be ill than to treat them when actually there is no need to do so, and as a precaution and in fear of relapse recommend long-term use of medicines (43). Research has suggested that the act of prescribing in itself might also suggest a biological basis for a problem (44), and that it appears that doctors are less willing to consider non-drug treatments if drug therapy is available, even when there is no evidence that pharmacotherapy is superior (45).

\section{RISK OF OVERDIAGNOSIS AND OVERTREATMENT}

One pathway to overdiagnosis can be through disease boundaries being widened and treatment thresholds lowered to a point where a medical label and subsequent therapy may cause people more harm than good (28). This broadening of diagnostic criteria is argued to reflect medicalization as much as discovery of previously undetected sick people $(35,46-49)$. Nonmedical problems have become medical ones with risking leading to overdiagnosis and overtreatment as the definition of what constitutes an abnormality gets increasingly broader (50).

Concern for the harm and costs of overdiagnosis and overtreatment is now gaining momentum, as the discussion of risk assessment and suggestions of pre-disease progress in the scientific debate $(51,52)$. Missed, delayed, or incorrect diagnoses can lead to inappropriate patient care, poor patient outcomes, and increased costs (53). In the United States, it has been estimated that between $\$ 158$ billion and $\$ 226$ billion was wasted on overtreatment in 2011 (54), and that the cost of medicalization in 2005 corresponded to almost $4 \%$ of the total domestic expenditures on health care that year, or $\$ 77$ billion (55). Thus, overdiagnosing depression "just in case" or because of a risk assessment may take its toll both health-wise and financially. One study found overdiagnosis and overtreatment of depression to be common in community settings in the U.S. (56).

Whether the public benefits from taking more and more medicines for increasingly broadly defined disease is open to serious question. Critics like Marcia Angell argues, for instance, that one could make a strong argument that Americans with minor ailments suffer more from overmedication, and all the side effects and drug interactions that go with it, than from undermedication (48). Thus, overdiagnosing depression "just in case" or because of a risk assessment may take its toll both health-wise and financially.

\section{THE DEVIL IN THE DETAILS}

Maybe, the devil is in the details. The "one in four" figure for mental illness prevalence, widely quoted as it is, has an unclear origin (57). Is it even reasonable that $27 \%$ of the American and European population is estimated to suffer from mental disorders (or 38\% Europeans depending on how many disorders are included)? Or is that approximately $8.5 \%$ of the Nordic population prescribed as antidepressant medication? (58). Or does it instead tell us something about the contemporary global community and our view of health and ill health? Pharmaceutical companies have for some time been accused of "disease mongering" $(28,59)$, whereby a "new condition" is promoted as a major public health problem in order to create a market for treatment, often without the public's knowledge, sometimes referred to as the "public healthification" of social problems (60). And there is also the issue of alleged financial ties not only between the members of the DSM panels and the pharmaceutical industry $(61,62)$ but also between industry and doctors responsible for clinical practical guidelines for other medical conditions as well (63).
If normal events are misdiagnosed as depression, this will risk leaving those who are depressed untreated (extended waiting lists to health care, wrong medications, or lack of resources) and thereby create undertreatment and overtreatment simultaneously. If depression is going to be viewed as a growing public health problem, there needs to be a distinction between ill health problems that are medical problems and those that are not.

\section{SUMMARY}

It is evident that there are conflicting views regarding the officially proclaimed widespread existence of mental disorders, and depression in particular. On the one hand, we face descriptions of a growing public health burden and risk, but on the other hand we have descriptions of overdiagnosis and overtreatment. Certainly, from a public health perspective anyway, a medical approach to mental disorders would be troublesome, since increasing medicalization furthermore risks individualizing mental problems that may have other sources and thereby moves the focus away from the social and political context of ill health, for instance, poverty and inequality. For the sake of public health, arguments for increased diagnosis must therefore be related to a possible danger of medicalizing social problems and life crises. By including people with mild problems in estimates of mental illness, we risk losing support for treating those people who have legitimate disorders.

\section{ACKNOWLEDGMENTS}

The author would like to thank Anna Meeuwisse, Lund University, and Tommy Svensson, Linköping University for providing valuable comments on previous versions of the manuscript. Andreas Vilhelmsson is a researcher with the Department of Clinical Sciences, Division of Social Medicine, and Global Health at Lund University.

\section{REFERENCES}

1. World Health Organization (WHO). Mental Health: New Understanding, New Hope. Geneva: World Health Organization (2001).

2. World Health Organization (WHO). Promoting Mental Health: Concepts, Emerging Evidence, Practice: A Summary Report/A Report From the World Health Organization, Department of Mental Health and Substance Abuse in Collaboration with the Victorian Health Promotion Foundation (VicHealth). Geneva: World Health Organization (2004). 
3. World Health Organization (WHO). The Global Burden of Disease: 2004 Update. Geneva: World Health Organization (2008).

4. Cassano P, Fava M. Depression and public health: an overview. J Psychosom Res (2002) 53:849-57. doi:10.1016/S0022-3999(02)00304-5

5. Whiteford HA, Degenhardt L, Rehm J, Baxter AJ, Ferrari AJ, Erskine $\mathrm{HE}$, et al. Global burden of disease attributable to mental and substance use disorder: findings from the Global Burden of Disease Study 2010. Lancet (2013) 382:1575-86. doi:10.1016/S0140-6736(13)61611-6

6. Bloom DE, Cafiero ET, Jané-Llopis E, AbrahamsGessel S, Bloom LR, Fathima S, et al. The Global Economic Burden of Noncommunicable Diseases. Geneva: World Economic Forum (2011).

7. Kessler RC, Chiu WT, Demler O, Merikangas KR, Walters EE. Prevalence, severity, and comorbidity of 12-month DSM-IV disorders in the National Comorbidity Survey Replication. Arch Gen Psychiatry (2005) 62:617-27. doi:10.1001/ archpsyc.62.6.617

8. Wittchen H-U, Jacobi F. Size and burden of mental disorders in Europe - a critical review and appraisal of 27 studies. Eur Neuropsychopharmacol (2005) 15:357-76. doi:10.1016/j.euroneuro.2005. 04.012

9. Wittchen H-U, Jacobi F, Rehm J, Gustavsson A, Svensson M, Jönsson B, et al. The size and burden of mental disorders and other disorders of the brain in Europe 2010. Eur Neuropsychopharmacol (2011) 21:655-79. doi:10.1016/j.euroneuro. 2011.07 .018

10. Stefansson C-G. Major public health problems - mental ill-health. Scand J Public Health (2006) 34(Suppl 67):87-103. doi:10.1080/ 14034950600677105

11. Danielsson M, Berlin M. Health in the working-age population. Health in Sweden: the National Public Health Report. Scand J Public Health (2012) 40(Suppl 9):72-94. doi:10.1177/1403494812459464

12. Lager A, Berlin M, Heimerson I, Danielsson M. Young people's health. Health in Sweden: the National Public Health Report 2012. Scand J Public Health (2012) 40(Suppl 9):42-71. doi:10.1177/ 1403494812459459

13. Lennartsson C, Heimerson I. Elderly people's health. Health in Sweden: the National Public Health Report 2012. Scand J Public Health (2012) 40(Suppl 9):95-120. doi:10.1177/ 1403494812459468

14. Breslau N, Roth T, Rosenthal L, Andreski P. Sleep disturbance and psychiatric disorders: a longitudinal epidemiological study of young adults. Biol Psychiatry (1996) 39:411-8. doi:10.1016/00063223(95)00188-3

15. Chang PP, Ford DE, Mead LA, Cooper-Patrick L, Klag MJ. Insomnia in young men and subsequent depression. Am J Epidemiol (1997) 146:105-14. doi:10.1093/oxfordjournals.aje.a009241

16. Ringbäck Weitoft G, Rosén M. Is perceived nervousness and anxiety a predictor of premature mortality and severe morbidity? A longitudinal follow up of the Swedish survey of living conditions. J Epidemiol Community Health (2005) 59:794-8. doi:10.1136/jech.2005.033076
17. Gale CR, Batty GD, Osborn DP, Tynelius P, Whitley E, Rasmussen F. Association of mental disorders in early adulthood and later psychiatric hospital admissions and mortality in a cohort study of more than 1 million men. Arch Gen Psychiatry (2012) 69(8):823-31. doi:10.1001/ archgenpsychiatry.2011.2000

18. Goodwin R, Olfson M. Treatment of panic attack and risk of major depressive disorder in the community. Am J Psychiatry (2001) 158:1146-8. doi: 10.1176/appi.ajp.158.7.1146

19. Koivumaa-Honkanen H, Honkanen R, Viinamäki H, Heikkilä K, Kaprio J, Koskenvou M. Life satisfaction and suicide: a 20-year follow-up study. $A m$ J Psychiatry (2001) 158:433-9. doi:10.1176/appi. ajp.158.3.433

20. Stein MB, Fuetsch M, Müller N, Höfler M, Lieb $\mathrm{R}$, Wittchen HU. Social anxiety disorder and the risk of depression. Arch Gen Psychiatry (2001) 58:251-6. doi:10.1001/archpsyc.58.3.251

21. Wittchen H-U, Beesdo K, Bittner A, Goodwin RD. Depressive episodes - evidence for causal role of primary anxiety disorders? Eur Psychiatry (2003) 18:384-93. doi:10.1016/j.eurpsy.2003.10.001

22. Rang HP, Dale MM, Ritter JM, Flower RJ. Rang and Dale's Pharmacology. Edinburgh: Churchill Livingstone (2007).

23. Lönnqvist J. Major psychiatric disorders in suicide and suicide attempters. In: Wasserman D, Wasserman C, editors. Oxford Textbook of Suicidology and Suicide Prevention: A Global Approach. Oxford: Oxford University Press (2009). p. 275-86.

24. Depression. Available from: www.who.int/ mediacentre/factsheets/fs369/en/index.html\#

25. Busfield J. Mental Illness. Cambridge: Polity Press (2011).

26. Healy D. Pharmageddon. Berkeley: University of California Press (2012).

27. Horwitz AV, Wakefield JC. Loss of Sadness: How Psychiatry Transformed Normal Sorrow into Depressive Disorder. Oxford: Oxford University Press (2007).

28. Moynihan R, Doust J, Henry D. Preventing overdiagnosis: how to stop harming the healthy. $B M J$ (2012) 344:e3502. doi:10.1136/bmj.e3502

29. Rose N. Disorders without borders? The expanding scope of psychiatric practice. Biosocieties (2006) 1:465-84. doi:10.1017/S1745855206004078

30. Dubos R. The Mirage of Health: Utopias, Progress, and Biological Change. New Brunswick: Rutgers University Press (1959).

31. Garrett L. Betrayal of Trust. The Collapse of Global Public Health. New York: Hyperion (2000).

32. Helman C. Culture, Health and Illness. Oxford: Oxford University Press (2007).

33. Rose N. The Politics of Life Itself. Biomedicine, Power, and Subjectivity in the Twenty-First Century. Princeton: Princeton University Press (2007).

34. Jutel A, Nettleton S. Towards a sociology of diagnosis: reflections and opportunities. Soc Sci Med (2011) 73:793-800. doi:10.1016/j.socscimed.2011. 07.014

35. Frances A. The first draft of DSM-V. BMJ (2010) 340:492. doi:10.1136/bmj.c1168

36. Beck U. Risk Society: Towards a New Modernity. London: Sage Publications (1992).

37. Beck U. World Risk Society. Cambridge: Polity Press (1999).
38. Helén I. The depression paradigm and beyond: the practical ontology of mood disorders. Sci Stud (2011) 24(1):81-112.

39. Conrad P. The Medicalization of Society. On the Transformation of Human Conditions into Treatable Disorders. Baltimore: The Johns Hopkins University Press (2007).

40. Ebeling M. 'Get with the Program!' Pharmaceutical marketing, symptom checklists and selfdiagnosis. Soc Sci Med (2011) 73:825-32. doi:10. 1016/j.socscimed.2011.05.054

41. Healy D. Medical partisans? Why doctors need conflicting interests. Aust N Z J Psychiatry (2012) 46(8):704-7. doi:10.1177/0004867412454197

42. American Psychiatric Association, APA. Diagnostic and Statistical Manual of Mental Disorders. Fourth Edition. Text Revision. Washington, DC: American Psychiatric Association (2000).

43. Busfield J. 'A pill for every ill': explaining the expansion in medicine use. Soc Sci Med (2010) 70:934-41. doi:10.1016/j.socscimed.2009.10.068

44. Cohen CI. The biomedicalization of psychiatry: a critical overview. Community Ment Health J (1993) 29(6):509-21. doi:10.1007/BF00754260

45. Lexchin J. Lifestyle drugs: issues for debate. CMAJ (2001) 164(10):1449-51.

46. Wakefield JC. The concept of mental disorder: diagnostic implications of the harmful dysfunction analysis. World Psychiatry (2007) 6:149-56.

47. Wakefield JC, Schmitz MF, First MB, Horwitz AV. Extending the bereavement exclusion for major depression to other losses. Arch Gen Psychiatry (2007) 64:433-40. doi:10.1001/ archpsyc.64.4.433

48. Angell M. The Truth About the Drug Companies: How they Deceive us and What to do About it. New York: Random House (2004).

49. Goldacre B. Bad Pharma: How Drug Companies Mislead Doctors and Harm Patients. London: Fourth Estate (2012).

50. Welch G, Schwartz L, Woloshin S. Overdiagnosed: Making People Sick in the Pursuit of Health. Boston: Beacon Press (2011).

51. Godlee F. Preventing overdiagnosis. BMJ (2012) 344:e3783. doi:10.1136/bmj.e3783

52. Sheldon T. Reserve antidepressants for cases of severe depression, Dutch doctors are told. BMJ (2012) 344:e4211. doi:10.1136/bmj.e4211

53. McDonald KM, Matesic B, Contopoulos-Ioannidis DG, Lonhart J, Schmidt E, Pineda $\mathrm{N}$, et al. Patient safety strategies targeted at diagnostic errors: a systematic review. Ann Intern Med (2013) 158:381-9. doi:10.7326/0003-4819-158-5201303051-00004

54. Berwick DM, Hackbarth AD. Eliminating waste in US health care. JAMA (2012) 307(14):1513-6. doi:10.1001/jama.2012.362

55. Conrad P, Mackie T, Mehrotra A. Estimating the costs of medicalization. Soc Sci Med (2010) 70(12):1943-7. doi:10.1016/j.socscimed.2010.02. 019

56. Mojtabai R. Clinician-identified depression in community settings: concordance with structuredinterview diagnoses. Psychother Psychosom (2013) 82:161-9. doi:10.1159/000345968

57. Ginn S, Horder J. "One in four" with a mental health problem: the anatomy of a statistic. BMJ (2012) 344:e1302. doi:10.1136/bmj.e2851 
58. Vilhelmsson A. Depression and antidepressants: a Nordic perspective. Front Public Health (2013) 1:30. doi:10.3389/fpubh.2013.00030

59. Moynihan R, Heath I, Henry D. Selling sickness. The pharmaceutical industry and disease mongering. BMJ (2002) 324:886-91. doi:10.1136/ bmj.324.7342.886

60. Meyer IH, Schwartz S. Social issues as public health: promise and peril. Am J Public Health (2000) 90(8):1189-91. doi:10.2105/AJPH.90.8.1189

61. Cosgrove L, Krimsky S, Vijayaraghavan M, Schneider L. Financial ties between DSM-IV panel members and the pharmaceutical industry. Psychother Psychosom (2006) 75:154-60. doi:10.1159/ 000091772

62. Cosgrove L, Krimsky S. A comparison of DSM-IV and DSM-5 panel members' financial associations with industry: a pernicious problem persists. $P L O S$ Med (2012) 9(3):e1001190. doi:10.1371/journal. pmed.1001190

63. Neuman J, Korenstein D, Ross JS, Keyhani S. Prevalence of financial conflicts of interest among panel members producing clinical practical guidelines in Canada and United States: cross sectional study. BMJ (2011) 343:d5621. doi:10.1136/bmj.d5621

Conflict of Interest Statement: The author declares that no support was given from any organization for the submitted work; that there are no financial relationships with any organizations that might have an interest in the submitted work; that no other relationships or activities exist that could have influenced the submitted work.
Received: 02 September 2014; accepted: 29 September 2014; published online: 14 October 2014.

Citation: Vilhelmsson A (2014) The devil in the details: public health and depression. Front. Public Health 2:192. doi: 10.3389/fpubh.2014.00192

This article was submitted to Epidemiology, a section of the journal Frontiers in Public Health.

Copyright (c) 2014 Vilhelmsson. This is an openaccess article distributed under the terms of the Creative Commons Attribution License (CC BY). The use, distribution or reproduction in other forums is permitted, provided the original author(s) or licensor are credited and that the original publication in this journal is cited, in accordance with accepted academic practice. No use, distribution or reproduction is permitted which does not comply with these terms. 